\title{
Dampak Penggunaan Smartphone Dalam Perkembangan Kognitif Siswa Kelas V SDI Darul Huda
}

\author{
Tb M Qadar R ${ }^{* 1}$, Sifta Firdiyah ${ }^{2}$, Siti Mucliyana ${ }^{3}$ \\ ${ }^{1,2,3}$ Program Studi S1 Pendidikan Guru Sekolah Dasar (PGSD) Fakultas Keguruan dan Ilmu \\ Pendidikan (FKIP) Universitas Muhammadiyah Tangerang \\ E-mail: ${ }^{* 1}$ qadarramadhan@ gmail.com, ${ }^{2}$ sfirdiyah@ gmail.com, \\ ${ }^{3}$ uchumuchliyanah8@gmail.com
}

\begin{abstract}
Abstrak
Perkembangan Kecerdasan Kognitif berkaitan dengan potensi intelektual yang dimiliki individu, yakni kemampuan untuk berfikir dan memecahkan masalah. Aspek kognitif juga dipengaruhi oleh perkembangan sel-sel syaraf pusat di otak. dari 90 Siswa SDI Darul Huda yang terdapat di Kelas Va, Vb, dan Vc, Siswa yang di Fasilitasi Smartphone oleh Orangtuanya adalah mencapai $93.75 \%$ peserta didik pengguna smartphone, atau 80 Orang dan 6,25\% tanpa smartphone atau hanya berkisar 5 orang sajaPenggunaan smartphone dalam kehidupan sehari - hari manfaatnya dapat dirasakan dengan memudahkan komunikasi bagi para penggunanya dan juga sebagai sarana hiburan, juga sebagai bentuk pengenalan terhadap Ilmu Pengetahuan dan tehnologi bagi generasi awal sebagai sarana melek tehnologi, dampak negative yang ditimbulkan seperti, menjadikan kecanduan terhadap anak-anak dibawah usia remaja, tingkat keinginan belajar menurun saat berada disekolah maupun dirumah dan anak anak akan malas bergerak dan sebagainya. Sehingga perlu ada pengenalan dalam bentuk muatan lokal atau mata pelajaran tambahan di sekolah, yang mengarahkan penggunaan smartphone bagi peserta didik untuk perkembangan ke arah positive.
\end{abstract}

Kata Kunci-Perkembangan Kecerdasan Kognitif, Dampak Smartphone

\begin{abstract}
Cognitive Intelligence development is related to intellectual potential of the individual, the ability of think and problems solve. The cognitive aspect is also influenced by the development of the brain's central nerve cells. The use of smartphones in daily life can be felt by facilitating communication for its users and also as a means of entertainment, as well as a form ofintroduction to Science and technology for early generations as a means of technological literacy, the negative impacts caused such as, making addiction to children under age teenager, the level of desire to learn decreases when in school or at home and children will be lazy to move and ect. So there needs to be an introduction in the form of local content or additional subjects in schools, which direct the use of smartphones for students to progress in a positive direction.
\end{abstract}

Keywords-Cognitive Intelligence development, Smartphone Negative Impacts 


\section{PENDAHULUAN}

\subsection{Permasalahan}

Penggunaan Smartphone digunakan oleh semua kalangan baik orang tua, pemuda, maupun anak - anak, Penggunaan smartphone dalam kehidupan sehari - hari manfaatnya dapat dirasakan dengan memudahkan komunikasi bagi para penggunanya dan juga sebagai sarana hiburan, juga sebagai bentuk pengenalan terhadap Ilmu Pengetahuan dan tehnologi bagi generasi awal sebagai sarana melek tehnologi, namun yang harus dilakukan penelitian mendalam adalah penggunaan Telpon Pintar (smartphone) pada anak - anak dibawah usia remaja, dampak negative yang ditimbulkan seperti, menjadikan kecanduan terhadap anak-anak dibawah umur, tingkat keinginan belajar menurun saat berada disekolah maupun dirumah dan anak anak akan malas bergerak dan sebagainya.

Theva Nithy (2018) dalam artikelnya Survei Tentang Smartphone \& Tablet Hasilnya Mengejutkan, menjelelaskan:

...TheAsiaParent Insight bersama Samsung Kidstime melalui mobile device Usage Among Young Kids yang diselenggarakan pada awal tahun 2014, sebanyak 2500 orang tua di Singapura, Thailand, Indonesia, Malaysia, dan Filifina menjadi responden dalam survei, hasilnya adalah $98 \%$ persen orang tua memperbolehkan anaknya menggunakan Smartphone/Tablet. Dengan alasan untuk hiburan, pengenalan Tehnologi dan membuat mereka sibuk.

Penggunaan Untukdi Indonesia, banyak peserta didik yang masih duduk di bangku Sekolah Dasar (SD) yang berkisar umur 7-12 tahun dibebaskan untuk memainkan berbagai jenis smartphone, padahal anak anak dibawah umur belum begitu penting untuk memiliki atau menggunakan smartphone untuk membantu pekerjaan sehari harinya. Lain halnya remaja atau orang dewasa yang lebih membutuhkan smartphone sebagai media untuk mencari informasi maupun memberikan informasi. Dampak dan pengaruh smartphone bagi perkembangan anak harus manjadi perhatian serius baik bagi para pendidik maupun orangtua namun tertutupnya anak dengan perkembangan tehknologi kekinian juga dapat berdampak terhadap sikap dan prilaku anak dalam pergaulan, anak yang tidak mengenal tehnologi akan diperlakukan oleh temannya sebagai seorang yang ketinggalan zaman. Karena itu akibat dari dampak negative maupun dampak positifnya, harus ada sebuah kajian yang dapat memberikan ukuran dan batasan terhadap penggunaan smartphone agar dapat diterapkan untuk Perkembangan terbaik bagi anak peserta didik khususnya bagi anak - anak pelajar di Sekolah Dasar.

Oleh karena itu Penelitian mendalam tentang dampak dibalik penggunaan smartphone bagi anak- anak perlu digiatkan agar generasi penerus Bangsa Indonesia dapat berkembang secara optimal baik dalam segi perkembangan kognitif maupun emosional, dan secara khusus agar para siswa dapat dipantau dan juga dianalisa secara objektif tentang dampak - dampak positive maupun negative penggunaan Smartphone bagi Peserta didik Kelas V (Lima) SD Darul Huda.

\subsection{Landasan Teori}

Perkembangan dapat diartikan sebagai proses perubahan kuantitatif dan kualitatif individu dalam rentang kehidupnnya, mulai dari masa konsepsi, masa bayi, masa kanak-kanak, masa remaja, sampai masa dewasa. Perkembangan dapat diartikan juga sebagai suatu proses perubahan dalam diri individu atau organisme, baik fisik (jasmaniah) maupun psikis (rohaniah) menuju tingkat kedewasaan atau kematangan yang berlangsung secara sistematis, progesif, dan berkesinambungan (Syamsu, 2011).

Desminta (2005) menyatakan bahwa Perkembangan kognitif adalah salah satu aspek perkembangan manusia yang berkaitan dengan pengertian (pengetahuan), yaitu semua proses psikologis yang berkaitan dengan bagaimana individu mempelajari dan memikirkan lingkungannya. Jp. Caplin (2009) menjelaskan bahwa kognisi adalah konsep umum yang 
mencakup semua bentuk pengenal, termasuk di dalamnya mengamati, melihat, memperhatikan, memberikan, menyangka, membayangkan, memperkirakan, menduga dan menilai Kognitif adalah sebuah istilah yang digunakan oleh psikolog untuk menjelaskan semua aktivitas mental yang berhubungan dengan persepsi, pikiran, ingatan, dan pengolahan informasi yang memungkinkan seseorang memperoleh pengetahuan, memecahkan masalah, dan merencanakan masa depan, atau semua proses psikologis yang berkaitan dengan bagaimana individu mempelajari, memperhatikan, mengamati, membayangkan, memperkirakan, menilai dan memikirkan lingkungannya. Kederdeasan kognitif harus dibedakan dengan kecerdasan emosional, yang berkaitan dengan perasaan anak. Istilah kecerdasan emosional pertama kali dilontarkan tahun 1990 oleh psikolog Peter Salovey dari Harvard University dan John Mayer dari University of New Hampshire untuk menerangkan kualitas-kualitas emosional yang tampaknya penting bagi keberhasilan. Kualitas-kualitas ini antara lain adalah; Empati, mengungkapkan dan memahami perasaan, mengendalikan amarah, kemandirian, kemampuan menyesuaikan diri, disukai, kemampuan memecahkan masalah antarpribadi, ketekunan, kesetiakawanan, keramahan, dan sikap hormat (Shapiro, 2001). Kecerdasan emosional adalah kemampuan seseorang mengatur kehidupan emosinya dengan inteligensi (to manage our emotional life with intelligence), menjaga keselarasan emosi dan pengungkapannya (the appropriateness of emotion and its expression) melalui keterampilan kesadaran diri, pengendalian diri, motivasi diri, empati, dan keterampilan sosial (Bahtiar, 2009).

\subsection{Penelitian Terdahulu}

Ada Penelitian terdahulu yang berkaitan dengan dampak penggunaan smartphone bagi siswa, yaitu:

\begin{tabular}{|c|c|c|c|c|c|}
\hline No. & $\begin{array}{l}\text { Penelitian } \\
\text { Tahun }\end{array}$ & Judul Penelitian & Persamaan & Perbedaan & Hasil Penelitian \\
\hline 1. & $\begin{array}{l}\text { Tania Clara } \\
\text { Dewanti, } \\
\text { Widada, } \\
\text { Triyono } \\
(2016)\end{array}$ & $\begin{array}{l}\text { Hubungan } \\
\text { Keterampilan } \\
\text { Sosial Dan } \\
\text { Penggunaan } \\
\text { Gadget Smartphone } \\
\text { Dengan } \\
\text { Prestasi Belajar } \\
\text { Siswa SMA Negeri } \\
9 \\
\text { Malang }\end{array}$ & $\begin{array}{l}\text { Penggunan } \\
\text { Smartphone } \\
\text { dan kajian } \\
\text { terhadap } \\
\text { dampaknya }\end{array}$ & $\begin{array}{l}\text { Penelitian di } \\
\text { Fokuskan } \\
\text { kepada anak } \\
\text { usia SMA. }\end{array}$ & \begin{tabular}{lr}
\multicolumn{2}{l}{ ada hubungan } \\
antara keterampilan \\
sosial \\
penggunaan gadget \\
smartphone dengan \\
prestasi belajar \\
siswa \\
SMA Negeri 9 \\
Malang
\end{tabular} \\
\hline 2. & $\begin{array}{l}\text { Zulfikar } \\
\text { Adilla } \\
\text { Sukarno, Prih } \\
\text { Hardinto } \\
(2018)\end{array}$ & $\begin{array}{lr}\text { Pengaruh } & \\
\text { Penggunaan } & \\
\text { Gadget, } & \text { Minat } \\
\text { Belajar } & \text { Dan } \\
\text { Kecerdasan } & \\
\text { Emosional } & \\
\text { Terhadap } & \text { Hasil } \\
\text { Belajar } & \text { Siswa } \\
\text { Kelas Xi } & \text { Iis Pada } \\
\text { Mata } & \text { Pelajaran } \\
\text { Ekonomi } & \text { Di } \\
\text { SMAN 1 Kepanjen }\end{array}$ & $\begin{array}{l}\text { Penggunan } \\
\text { Smartphone } \\
\text { dan kajian } \\
\text { terhadap } \\
\text { dampaknya }\end{array}$ & $\begin{array}{l}\text { Penelitian di } \\
\text { Fokuskan } \\
\text { kepada anak } \\
\text { usia SMA. }\end{array}$ & $\begin{array}{l}\text { efek penggunaan } \\
\text { gadget sekitar } \\
10,43 \% \text {, pengaruh } \\
\text { minat belajar sekitar } \\
27,22 \% \text { dan efek } \\
\text { kecerdasan } \\
\text { emosional adalah } \\
\text { sekitar } 22,75 \% \text {. }\end{array}$ \\
\hline 3. & $\begin{array}{l}\text { Khaeriyah } \\
\text { Khaeriyah, } \\
\text { Amir } \\
\text { Mahmud }\end{array}$ & $\begin{array}{l}\text { Pengaruh Intensitas } \\
\text { Penggunaan } \\
\text { Smartphone Dan } \\
\text { Pemanfaatan }\end{array}$ & $\begin{array}{l}\text { Penggunan } \\
\text { Smartphone } \\
\text { dan kajian } \\
\text { terhadap }\end{array}$ & $\begin{array}{l}\text { Intensitas } \\
\text { penggunaan } \\
\text { smartphone } \\
\text { terhadap }\end{array}$ & $\begin{array}{l}\text { Intensitas } \\
\text { penggunaan } \\
\text { smartphone terhadap } \\
\text { pemanfaatan internet }\end{array}$ \\
\hline
\end{tabular}




\begin{tabular}{|c|c|c|c|c|c|}
\hline & (2017) & $\begin{array}{lr}\text { Internet } & \text { Terhadap } \\
\text { Motivasi } & \text { Belajar } \\
\text { Dan Hasil } & \text { Belajar } \\
\text { Ekonomi } & \end{array}$ & dampaknya & $\begin{array}{l}\text { pemanfaatan } \\
\text { internet } \\
\text { sebagai } \\
\text { sumber } \\
\text { belajar }\end{array}$ & $\begin{array}{lr}\text { sebagai } & \text { sumber } \\
\text { belajar } & \text { sebesar } \\
17,2 \% \text { Intensitas } \\
\text { penggunaan } \\
\text { smartphone, } \\
\text { pemanfaatan internet } \\
\text { sebagai sumber } \\
\text { belajar dan motivasi } \\
\text { belajar berpengaruh } \\
\text { secara positif } \\
\text { terhadap hasil } \\
\text { belajar baik secara } \\
\text { langsung maupun } \\
\text { tidak langsung. }\end{array}$ \\
\hline 4. & $\begin{array}{l}\text { Green Ferry } \\
\text { Mandias, } \\
\text { (2017) }\end{array}$ & $\begin{array}{l}\text { Analisis Pengaruh } \\
\text { Pemanfaatan } \\
\text { Smartphone } \\
\text { Terhadap Prestasi } \\
\text { Akademik } \\
\text { Mahasiswa } \\
\text { Fakultas Ilmu } \\
\text { Komputer } \\
\text { Universitas Klabat }\end{array}$ & $\begin{array}{l}\text { Penggunan } \\
\text { Smartphone } \\
\text { dan kajian } \\
\text { terhadap } \\
\text { dampaknya }\end{array}$ & $\begin{array}{l}\text { Penelitian } \\
\text { difokuskan } \\
\text { pada } \\
\text { kalangan } \\
\text { mahasiswa }\end{array}$ & $\begin{array}{lr}\begin{array}{lr}\text { hubungan } \\
\text { signifikan }\end{array} & \text { yang } \\
\text { prestasi } & \text { mahasiswa } \\
\text { fakultas } & \text { ilmu } \\
\text { komputer } & \\
\text { Universitas } & \text { Klabat } \\
\text { ditunjukkan } & \text { dengan } \\
\text { angka dibawah 5\%. }\end{array}$ \\
\hline
\end{tabular}

\section{METODE PENELITIAN}

\subsection{Tempat dan Waktu Penelitian}

Lokasi penelitian ini dilakukan di Kelas V (lima) SDI Darul Huda Tangerang. Populasi penelitian ini adalah semua siswa kelas V (Lima) SDI Darul Huda Tangerang tahun ajaran 2020Waktu penelitian dilaksanakan pada bulan Februari 2020.

\subsection{Rumusan Masalah}

Berdasarkan latar belakang yang telah diungkapkan sebelumnya, maka penelitian ini diarahkan untuk menjawab permasalahan sebagai berikut: "Bagaimana Dampak Penggunaan Smartphone Dalam Perkembangan Kecerdasan Kognitif Dan Emosional Peserta Didik Di Kelas 5 (lima) SDI (Sekolah Dasar Islam) Darul Huda?" Permasalahan tersebut kami rinci melalui pertanyaan-pertanyaan penelitian sebagai berikut:

1. Apakah smartphone mempengaruhi Perkembangan Kecerdasan Kognitif dan Kecerdasan Emosional Peserta didik di Kelas 5 SDI Darul Huda?

2. Apakah dampak yang ditimbulkan dari penggunaan smartphone bagi Peserta didik di Kelas 5 SDI Darul Huda?

\subsection{Batasan Penelitian dan Sumber Data}

Berdasarkan rumusan masalah yang telah diungkapkan, maka perlu adanya batasanbatasan penelitian agar penelitian ini lebih terarah. Batasan-batasan penelitian yang diberikan sebagai berikut:

a. Penelitian ini dibatasi pada siswa Sekolah Dasar. 
b. Subyek penelitian adalah siswa SD kelas 5 SDI Darul Huda yang beralamat di Jl. Dahu No.45, RT.002/RW.006, Kel. Keroncong, Kec. Jaituwung, Kota Tangerang, Prov. Banten.

c. Indikator yang diukur adalah nilai yang didapat oleh siswa dalam kegiatan belajar dalam setiap mata pelajaran untuk mengetahui Perkembangan Kecerdasan Kognitif Siswa dan kemampuan berinteraksi sosial melalui lembar pengamatan dalam bentuk uraian/deskripsi untuk mengetahui Perkembangan kecerdasan Emosional Siswa.

Sedangkan Sumber data yang digunakan adalah dapat dibedakan menjadi 2 (dua), yaitu;

a. Data Primer adalah data yang diperoleh dari hasil mengamati dan juga melakukan wawancara, bersifat kualitatif maupun kuantitatif yang berhubungan dengan penggunaan gadget dan dampak bagi kecerdasan kognitif siswa Sekolah Dasar.

b. Data Sekunder adalah data yang diperoleh dari dokumen - dokumen yang ada pada Sekolah Dasar Islam Darul Huda, yaitu berupa nilai siswa, data lain berupa hasil penelitian maupun kepustakaan.

\subsection{Tujuan Penelitian}

Tujuan dari penelitian ini sebagai berikut:

1. Untuk memperoleh gambaran secara kuantitatif mengenai Perkembangan Kecerdasan Kognitif peserta didik Sekolah Dasar dan Perkembangan Kecerdasan Emosional Peserta didik Sekolah Dasar khususnya peserta didik SDI Darul Huda.

2. Untuk memperoleh alat evaluasi yang tepat untuk dapat menguji ketercapaian kemampuan aspek interaksisosial peserta didik melalui pembelajaranyang diberikan.

3. Untuk mengarahkan peserta didik dalam mendapatkan pengetahuan dan pengalaman lebih melalui interaksi sosial.

\subsection{Target Luaran}

Target luaran yang diharapkan pada kegiatan penelitian ini sebagai berikut:

1. Tersedianya instrumen yang valid dan reliable untuk mengukur Perkembangan Kecerdasan Kognitif dan Perkembangan Kecerdasan Emosional dalam hal peserta didik pengguna Smartphone.

2. Hasil-hasil penelitian yang bisa dijadikan bahan sebagai data-data dan fakta saat kegiatan ini dilakukan, bisa menjadi bahan kajian lanjutan untuk bahan kajian penyelesaian tugas akhir (skripsi) dan bisa dipublikasikan secara nasional melalui jurnal - jurnal pendidikan yang tersedia.

3. Sebagai bahan kajian, adapun program penelitian tindak lanjut yang bisa dilakukan sebagai berikut: bertambahnya peserta didik dan guru-guru dalam melakukan interaksi sosial.

\subsection{Jenis Penelitian dan Tehnik Pengambilan Sampel}

Jenis dalam penelitian ini yaitu kuantitatif dengan menggunakan rancangan penelitian Observasional Analitik dan pendekatan waktu penelitian Cross Sectional dimana pengambilan data terhadap beberapa variabel penelitian dilakukan pada satu waktu (Dharma, 2011). Mengingat target penelitian ini adalah siswa Sekolah dasar, maka metode yang Pada penelitian ini dibuat dengan menyusun lembar pertanyaan yang telah disiapkan dan juga melihat daftar nilai siswa dalam setiap mata pelajaran. Dalam penelitian ini Terdapat tigavariable utama penelitian, yaitu; penggunaan smartphone, tingkat ketergantungan smartphone dan interaksi sosial yang diteliti menggunakan lembar penelitian yang telah disiapkan, dan juga pengaruh penggunaan smartphone terhadap hasil belajar siswa yang dilihat dari nilai yang didapat oleh siswa dalam setiap mata pelajaran. Sampel dipilih dengan teknik Proportionate Stratified Random Sampling dengan pemilihan primary sampling unit yang dilakukan secara proporsional 
dalam satu kelas. Analisis uji bivariate menggunakan chi square dengan tingkat kepercayaan yang digunakan peneliti adalah 95\% (Sembilan Puluh Lima Persen).

\section{HASIL DAN PEMBAHASAN}

\section{Dampak Penggunaan Smartphone Dalam Perkembangan Kognitif Siswa Kelas V SDI Darul Huda}

Hasil data dilapangan menunjukan penggunaan Smartphone pada Siswa Kelas V(lima) Sekolah Dasar Darul Huda, dari 90 Siswa SDI Darul Huda yang terdapat di Kelas Va,Vb, dan Vc, Siswa yang di Fasilitasi Smartphone oleh Orangtuanya adalah mencapai $93.75 \%$ peserta didik pengguna smartphone, atau 80 Orang dan 6,25\% tanpa smartphone atau hanya berkisar 5 orang saja.

Intensitas penggunaan smartphone oleh siswa bervariasi dari mulai tidak menggunakan smartphone sampai dengan penggunaan smartphone dengna intensitas tinggi yang dilakukan oleh siswa SDI Darul Huda, Intensitas Rendah penggunaan juga dapat di hubungkan dengan penagawasan dan larangan orangtua agar anak tidak mengalami kecanduan smartphone, sementara itu intensitas tinggi penggunaan smartphone dapat menjadi sebuah tanda anak mengalami kecanduan terhadap smartphone. Para peneliti di King's College London (KCL) dalam artikel Bagus Pradana, (2019), menganalisis 41 studi yang diterbitkan sejak 2011 tentang penggunaan ponsel cerdas dan kesehatan mental. Merujuk pada hasil perunutan tersebut disimpulkan bahwa antara 10 persen hingga 30 persen anak-anak dan remaja tidak bisa lepas dari ponsel cerdas mereka. Ini berarti rata-rata 23 persen anak menunjukkan ciri-ciri 'problematic smartphone usage'(PSU) atau penggunaan ponsel cerdas yang bermasalah.

Dari hasil pengambilan data awal, sudah jelas terlihat pengenalan smartphone telah secara menyeluruh terjadi di usia Sekolah Dasar. Data penggunaan smartphone dapat di lihat dalam diagram berikut;Dalam data tersebut dapat dirangkum kedalam suatu garis besar data sebagai berikut:

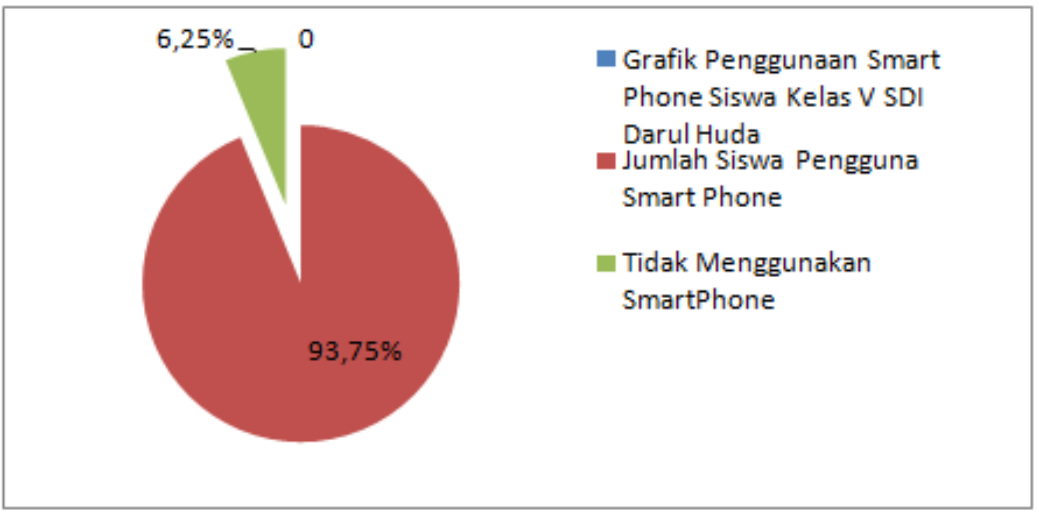

Gambar 1. Grafik Penggunaan Smartphone Siswa Kelas V SDI Darul Huda Sumber: Data Primer SDI Darul Huda

Selain melakukan pengambilan data penggunaan sampel, selanjutnya tim pencoba melakukan kajian mendalam antara intensitas penggunaan smartphone siswa Sekolah Dasar Islam (SDI) Darul Huda dan dampaknya bagi perkembangan kecerdasan kognitif anak. Bahwa dalam melakukan pengambilan sampel, tim telah menyiapkan lembar khusus yang dapat dijawab oleh siswa sekolah dasar dengan pertanyaan langsunga dalam wawancara singkat dengan siswa. Terdapat pariabel intensitas penggunaan smartphone dari mulai harian yaitu; < (Kurang dari) 1 Jam perhari , 1> ( lebih dari sampai) 3 jam Perhari, dan $3>$ (lebih dari sampai) 5 Jam Perhari, dengan Pariabel intensitas penggunaan mingguan, < (kurang dari) 2 hari dalam satu minggu, 2> (lebih dari) 4 hari dalam 1 minggu, 5> (lebih dari) 6 hari dalam 1 minggu, dan satu minggu full penggunaan smartphone. 
Sementara itu untuk mencari dampak yang ditimbulkan dari intensitas penggunaan smartphone terhadap perkembangan kognitif siswa Sekolah Dasar Islam (SDI) Darul Huda, tim melakukan pengambilan data sampel berupa nilai siswa dalam setiap mata pelajaran, dan mengambil 3 (tiga) nilai tertinggi siswa dan 3 (tiga) nilai terendah siswa, dan juga rata- rata nilai dari seluruh mata pelajaran. Data penelitian yang diperoleh tim di lapangan dapat di jelaskan dengan tabel berikut ini;

Tabel 1. Intensitas Penggunaan Smartphone Siswa Sekolah Dasar Islam (SDI) Darul Huda

\begin{tabular}{|c|c|c|c|c|c|c|c|}
\hline No & $\begin{array}{l}\text { Jumlah } \\
\text { Siswa }\end{array}$ & $\begin{array}{l}\text { Per } \\
\text { Hari }\end{array}$ & $\begin{array}{l}\text { Per } \\
\text { Minggu }\end{array}$ & $\begin{array}{l}\text { Aplikas } \\
\text { i }\end{array}$ & \multicolumn{3}{|l|}{ Data Nilai Siswa } \\
\hline 1 & 1 Orang & - & - & - & \multicolumn{3}{|c|}{$\begin{array}{l}\text { Nilai tertinggi: MP. Pjok }=90, \mathrm{MP} . \mathrm{Ski}=90 . \mathrm{MP} . \\
\text { B.indo }=88 \\
\text { Nilai terendah: MP. B.ing }=80, \mathrm{MP} . \mathrm{Mtk}=85, \mathrm{MP} \\
\text { Tik }=85 \\
\text { Nilai rata }- \text { rata dari seluruh MP. } 3,68=92\end{array}$} \\
\hline 2 & 2 Orang & $\begin{array}{l}\text { Kuran } \\
\mathrm{g} \text { dari } \\
1 \text { jam }\end{array}$ & $\begin{array}{l}\text { kurang } \\
\text { dari } 2 \\
\text { hari }\end{array}$ & $\begin{array}{l}\text { Game } \\
\text { offline. }\end{array}$ & $\begin{array}{l}\text { Nilai tertinggi } \\
\text { MP. Mtk : } 100 \\
\text { MP. Ipa }: 100 \\
\text { MP. Ips }: 100 \\
\text { Nilai terendah } \\
\text { MP. B.ing : } 80 \\
\text { MP. Btq : } 95 \\
\text { MP. B.indo : } 98 \\
\text { Nilai rata }- \text { rata } \\
\text { dari seluruh MP. } \\
\text { 3,88 }=97\end{array}$ & \multicolumn{2}{|c|}{$\begin{array}{l}\text { Nilai tertinggi } \\
\text { MP. Pkn }=100 \\
\text { MP. Ipa }=100 \\
\text { MP. B.pker }=100 \\
\text { Nilai terendah } \\
\text { MP. Pjok }=80 \\
\text { MP. Tik }=86 \\
\text { MP. Fiqih }=85 \\
\text { Nilai rata }- \text { rata dari seluruh } \\
\text { MP...3,8 }=95\end{array}$} \\
\hline 3. & 3 Orang & $\begin{array}{l}\text { Kuran } \\
\text { g dari } \\
1 \text { jam }\end{array}$ & $\begin{array}{l}2-4 \text { hari } \\
\text { dalam } \\
\text { satu } \\
\text { minggu }\end{array}$ & $\begin{array}{l}\text { video } \\
\text { dan film } \\
\text { non } \\
\text { pendidik } \\
\text { an, } \\
\text { game } \\
\text { Online }\end{array}$ & $\begin{array}{l}\text { Nilai tertinggi } \\
\text { MP. B.Arab } \\
=100 \\
\text { MP. Fiqih }=95 \\
\text { MP. Pjok }=98 \\
\text { Nilai terendah } \\
\text { MP. Mtk }=70 \\
\text { MP. B.ing }=72 \\
\text { MP. Pkn }=74 \\
\text { Nilai rata }- \text { rata } \\
\text { dari seluruh MP. } \\
3,52=88\end{array}$ & $\begin{array}{l}\text { Nilai } \\
\text { tertinggi } \\
\text { MP. Pai = 98 } \\
\text { MP. B.arab = } \\
100 \\
\text { MP. Ski = 90 } \\
\text { Nilai } \\
\text { terendah } \\
\text { MP. Pkn = } \\
72 \\
\text { MP. Tik = 85 } \\
\text { MP. B.ing } \\
=70 \quad \text { Nilai rata - } \\
\text { rata dari } \\
\text { seluruh MP. } \\
3,6=90 \quad\end{array}$ & $\begin{array}{l}\text { Nilai tertinggi } \\
\text { MP. Ski = 94 } \\
\text { MP. B.Arab = } \\
100 \\
\text { MP. Mtk }=100 \\
\text { Nilai terendah } \\
\text { MP. Pkn }=87 \\
\text { MP. Ips }=81 \\
\text { MP. B.ing = 82 } \\
\text { Nilai rata }- \text { rata } \\
\text { dari seluruh MP. } \\
3,76=94\end{array}$ \\
\hline 4. & 2 Orang & $\begin{array}{l}1-3 \\
\text { jam }\end{array}$ & $\begin{array}{ll}\text { kurang } & \\
\text { dari } & 2 \\
\text { hari } & \end{array}$ & $\begin{array}{l}\text { Game } \\
\text { offline } \\
\text { Game } \\
\text { Online }\end{array}$ & $\begin{array}{l}\text { Nilai tertinggi } \\
\text { MP. B.arab = } \\
100 \\
\text { MP. Pkn }=100 \\
\text { MP. Mtk }=92 \\
\text { Nilai terendah } \\
\text { MP. Ski }=70 \\
\text { MP. Pai }=85 \\
\text { MP. Ipa }=85\end{array}$ & $\begin{array}{l}\text { Nilai tertinggi } \\
\text { MP. Pai }=95 \\
\text { MP. Mtk }=100 \\
\text { MP. Ski }=90 \\
\text { Nilai terendah } \\
\text { MP. B.ing }=72 \\
\text { MP. Ips }=88 \\
\text { MP. Tik }=85 \\
\text { Nilai rata }- \text { rata }\end{array}$ & a dari seluruh MP. \\
\hline
\end{tabular}




\begin{tabular}{|c|c|c|c|c|c|c|c|}
\hline & & & & & $\begin{array}{l}\text { Nilai rata }- \text { rata } \\
\text { dari seluruh } \\
\text { MP.3,64 }=91\end{array}$ & $3,67=94$ & \\
\hline 5. & 3 Orang & $\begin{array}{l}1-3 \\
\text { jam }\end{array}$ & $\begin{array}{l}2-4 \text { hari } \\
\text { dalam } \\
\text { satu } \\
\text { minggu }\end{array}$ & $\begin{array}{l}\text { Game } \\
\text { offline } \\
\text { Game } \\
\text { Online } \\
\text { video } \\
\text { dan film } \\
\text { non } \\
\text { pendidik } \\
\text { an }\end{array}$ & $\begin{array}{l}\text { Nilai tertinggi } \\
\text { MP. Pai }=100 \\
\text { MP. Btq }=98 \\
\text { MP. B. Arab } \\
=100 \\
\text { Nilai terendah } \\
\text { MP. Mtk }=80 \\
\text { MP. Ipa }=89 \\
\text { MP. B.ing }=80 \\
\text { Nilai rata }- \text { rata } \\
\text { dari seluruh MP. } \\
3,72=93\end{array}$ & 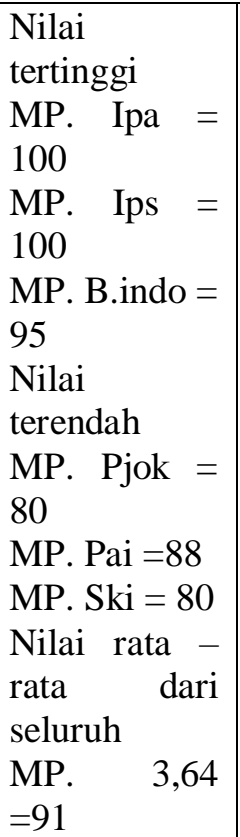 & $\begin{array}{l}\text { Nilai tertinggi } \\
\text { MP. Ski }=94 \\
\text { MP. B.Arab = } \\
100 \\
\text { MP. Mtk }=100 \\
\text { Nilai terendah } \\
\text { MP. Pkn }=87 \\
\text { MP. Ips }=91 \\
\text { MP. B.ing }=82 \\
\text { Nilai rata }- \text { rata } \\
\text { dari seluruh MP. } \\
\text { 3,76 }=94\end{array}$ \\
\hline 6. & 1 Orang & $\begin{array}{l}1-3 \\
\text { jam }\end{array}$ & $\begin{array}{l}5-6 \text { hari } \\
\text { dalam } \\
\text { satu } \\
\text { minggu }\end{array}$ & $\begin{array}{l}\text { Game } \\
\text { Online }\end{array}$ & \multicolumn{3}{|c|}{$\begin{array}{l}\text { Nilai tertinggi: MP. Pai }=100, \text { MP. Mtk }=100, \text { MP. } \\
\text { B.indo }=94 \\
\text { Nilai terendah: MP. B.ing }=80, \text { MP Fiqih }=85 . \text { MP. } \\
\text { Ski= } 70 \\
\text { Nilai rata }- \text { rata dari seluruh MP...3,76 }=94\end{array}$} \\
\hline 7. & 3 Orang & $\begin{array}{l}1-3 \\
\text { jam }\end{array}$ & $\begin{array}{l}\text { satu } \\
\text { minggu } \\
\text { full }\end{array}$ & $\begin{array}{l}\text { Game } \\
\text { Online }\end{array}$ & $\begin{array}{l}\text { Nilai tertinggi } \\
\text { MP. Ips =100 } \\
\text { MP. B.arab } \\
=100 \\
\text { MP. Ski }=90 \\
\text { Nilai terendah } \\
\text { MP. B.ing }=70 \\
\text { MP. Fiqih }=70 \\
\text { MP. Pai }=80 \\
\text { Nilai rata }- \text { rata } \\
\text { dari seluruh } \\
\text { MP...3,52 }=88\end{array}$ & $\begin{array}{l}\text { Nilai } \\
\text { tertinggi } \\
\text { MP. B.arab = } \\
100 \\
\text { MP. Ips } \\
=100 \quad \\
\text { MP. Mtk = } \\
91 \\
\text { Nilai } \\
\text { terendah } \\
\text { MP. B.ing = } \\
\text { MP. Pkn = } \\
80 \quad \text { MP. Ski = 80 } \\
\text { Nilai rata - } \\
\text { rata dari } \\
\text { seluruh } \\
\text { MP...3,52 } \\
=88\end{array}$ & $\begin{array}{l}\text { Nilai tertinggi } \\
\text { MP. B.arab = } \\
100 \\
\text { MP. Btq }=96 \\
\text { MP. Pkn }=95 \\
\text { Nilai terendah } \\
\text { MP. B.ing }=82 \\
\text { MP. Ipa }=84 \\
\text { MP. Pkn }=84 \\
\text { Nilai rata }- \text { rata } \\
\text { dari seluruh } \\
\text { MP...3,72=93 }\end{array}$ \\
\hline 8. & 1 Orang & $\begin{array}{l}3 \\
\text { sampai } \\
5 \text { jam }\end{array}$ & $\begin{array}{l}\text { satu } \\
\text { minggu } \\
\text { full }\end{array}$ & $\begin{array}{l}\text { Game } \\
\text { Online }\end{array}$ & \multicolumn{3}{|c|}{$\begin{array}{l}\text { Nilai tertinggi, MP. B.arab }=100, \text { MP. Ips }=100 \text {, } \\
\text { MP, Mtk }=91 \\
\text { Nilai terendah: MP. B.ing }=70, \text { MP. } P k n=80, \text { MP. } \\
\text { Ski }=80 \\
\text { Nilai rata }- \text { rata dari seluruh MP. } 3,52=88\end{array}$} \\
\hline
\end{tabular}

Data Primer dan Sekunder Kelas V (lima) SDI Darul Huda 

berikut:

Dari data yang diperoleh tersebut, dapat dianalisa ditarik sebuah kesimpulan sebgai

Pertama, anak yang menggunakan smartphone terkontrol dalam rata - rata harian dibawah 1 (satu) jam dan kurang dari 2 (dua) hari dalam waktu satu minggu, memiliki nilai rata - rata mata pelajaran yang jauh lebih unggul dari peserta didik lainnya yaitu nilai rata - rata mata pelajaran 97 (Sembilan Puluh tujuh), Kedua,anak yang menggunakan smartphone 1 (satu) s/d 3 (tiga) jam maksimal penggunaan harian dan lebih dari 2 (dua) hari dalam seminggu nilai rata- rata mata pelajaran jauh lebih rendah dibandingkan peserta didik yang menggunakan fasilitas smartphone kurang dari 1 (satu) jam perhari dan kurang dari 2 (dua) dalam satu minggu yaitu nilai rata - rata seluruh mata pelajaran adalah berkisar antara 92 (Sembilan Puluh Dua) s/d 94 (Sembilan Puluh Empat). Ketiga, anak yang menggunakan smartphone lebih dari 3 (tiga) jam perhari dan menggunakan seminggu penuh, meskipun nilai rata - rata mata pelajaran adalah sama dengan anak lainnya, namun dalam nilai mata pelajaran tertentu telihat jelas dalam mata pelajaran tertentu nilainya jauh lebih rendah dari rata - rata semua mata pelajaran. Hal ini berbeda dengan anak yang tidak menggunakan smartphone, nilai tertinggi dan terendah dari semua mata pelajaran tidak terlalu jauh yaitu nilai rata - rata 92 dan nilai terendah adalah 85 , peserta didik yang tidak menggunakan smartphone hanya tidak bisa mengungguli peserta didik lainnya yang menggunakan smartphone dalam mata pelajaran bahasa inggris, keunggulan anak yang menggunakan smartphone dalam pembelajaran Bahasa Inggris lebih diakibatkan karena Faktor Penggunaan aplikasi sarana hiburan dalam smartphone yang lebih banyak menggunakan bahasa inggris.

Dari data diatas dapat ditarik kesimpulan tentang dampak Penggunaan smart Phone dalam Perkembangan Kecerdasan Kognitif Peserta didik sebagai berikut; Penggunaan smartphone dapat menimbulkan efek positif selama penggunaan smartphone bagi peserta didik dibatasi yaitu dibawah 1 (satu) jam perhari dan kurang dari 2 (dua) hari selama 1 (satu) minggu, pembatasan itu juga berguna agar peserta didik dapat tetap fokus dalam melakukan kegiatan pembelajaran di sekolah maupun di rumah, sehingga kecerdasan kognitif tetap terbangun secara merata dalam semua mata pelajaran. Sedangkan penggunaan smartphone berlebihan yaitu diatas 1 (satu) jam perhari sampai diatas 3 (tiga) jam perhari dan lebih dari 2 (dua) hari dalam satu minggu dapat menyebabkan peserta didik tidak fokus disatu atau beberapa mata pelajaran. Dalam hal peserta didik yang tidak menggunakan smartphone adalah hanya tidak unggul dalam mata pelajaran bahasa inggris, tetapi dalam menerima mata pelajaran tingkat fokus lebih merata sebagaimana anak yang menggunakan smartphone dibatasi dibawah 1(satu) jam perhari dan kurang dari 2 (dua) hari dalam seminggu. Maka dapat juga disimpulkan garis besar penelitian dampak smartphone bagi perkembangan kecerdasan kognitif adalah mengurangi tingkat fokus dalam kegiatan pembelajaran disekolah.

Dari data yang dihimpun dilapangan, berupa pengamatan terhadap prilaku siswa, perbedaan peserta didik pengguna smartphone dengan peserta didik tanpa fasilitas smartphone, adalah anak yang menggunakan smartphone jauh lebih mudah dalam bergaul dengan teman teman sekelasnya, atau dengan kata lain, anak tanpa smartphone cenderung lebih menjadi pendiam di dalam kelasnya. Maka smartphone bagi perkembangan kecerdasan emosional peserta didik justru diperlukan untuk menghindari peserta didik dari prilaku persekusi (bullying) rasa minder atau tidak percaya diri karena dianggap sebagai seorang yang gagap tehnologi (Gaptek).

Berbeda dengan dampak penggunaan smartphone bagi Perkembangan Kecerdasan Kognitif, yang menjadikan peserta didik kurang fokus dalam melakukan kegiatan pembelajaran di sekolah maupun di rumah, dampak Penggunaan Smartphone bagi Perkembangan Emosional justru lebih kearah Positive, yaitu menjadikan karakteristik anak lebih mudah dalam berbaur dengan anak seusianya. Dalam situasi seperti ini, adalah sama halnya dengan pengenalan Tehnologi Komputer pada anak peserta didik di sekolah, maka perlu ada pengenalan dalam bentuk muatan lokal atau mata pelajaran tambahan di sekolah, yang mengarahkan penggunaan smartphone bagi peserta didik untuk perkembangan ke arah positive. Dengan masuknya smartphone kedalam kurikulum pendidikan anak usia Sekolah Dasar, dapat meminimalisir 
dampak negative yang ditimbulkan dari penggunaan smartphone berlebihan oleh peserta didik diluar institusi sekolah. Dan dapat meminimalisir tindakan Persekusi (bullying) terhadap teman sekelasnya yang dianggap tidak melek Tehnologi (gaptek), dan juga sikap minder atau pendiam peserta didik karena merasa lebih rendah dari anak lain yang seusia karena tidak mengenal smartphone dalam kehidupannya.

\section{KESIMPULAN}

Berdasarkan Hasil Penelitian dan Pembahasan mengenai dampak penggunaan Smartphone, dalam perkembangan kecerdasan Kognitif Siswa Kelas V SDI Darul Huda, dapat di peroleh kesimpulan sebagai berikut;

1. Salah satu perkembangan teknologi yang sangat mempengaruhi pola pikir manusia adalah gadget. Berkaitan dengan pengaruh gadget terhadap interaksi sosial pada siswa SD ternyata memberikan pengaruh positif. Terutama mencegah terjadinya Persekusi (bullying) dan menambah rasa percaya diri peserta didik karena mengenal tehnologi, tetapi seringnya peserta didik berinteraksi dengan smartphone dan berlebihan mempengaruhi daya pikir peserta didik terhadap sesuatu diluar hal tersebut. Smartphone dapat mengurangi tingkat fokus peserta didik dalam menerima pembelajaran.

2. Penggunaan smartphone dapat menimbulkan efek positive selama penggunaan smartphone bagi peserta didik dibatasi yaitu dibawah 1 (satu) jam perhari dan kurang dari 2 (dua) hari selama 1 (satu) minggu, pembatasan itu juga berguna agar peserta didik dapat tetap fokus dalam melakukan kegiatan pembelajaran di sekolah maupun di rumah, sehingga kecerdasan kognitif tetap terbangun secara merata dalam semua mata pelajaran. Sedangkan penggunaan smartphone berlebihan yaitu diatas 1 (satu) jam perhari sampai diatas 3 (tiga) jam perhari dan lebih dari 2 (dua) hari dalam satu minggu dapat menyebabkan peserta didik tidak fokus disatu atau beberapa mata pelajaran. Dalam hal peserta didik yang tidak menggunakan smartphone adalah hanya tidak unggul dalam mata pelajaran bahasa inggris, tetapi dalam menerima mata pelajaran tingkat fokus lebih merata sebagaimana anak yang menggunakan smartphone dibatasi dibawah 1(satu) jam perhari dan kurang dari 2 (dua) hari dalam seminggu.

3. Dampak smartphone bagi perkembangan kecerdasan kognitif adalah mengurangi tingkat fokus dalam kegiatan pembelajaran di sekolah.

\section{SARAN}

Pengenalan terhadap smartphone adalah di perlukan, Dalam situasi seperti ini, adalah sama halnya dengan pengenalan Tehnologi Komputer pada anak peserta didik di sekolah, maka perlu ada pengenalan dalam bentuk muatan lokal atau mata pelajaran tambahan di sekolah, yang mengarahkan penggunaan smartphone bagi peserta didik untuk perkembangan ke arah positive. Dengan masuknya smartphone kedalam kurikulum pendidikan anak usia Sekolah Dasar, dapat meminimalisir dampak negative yang ditimbulkan dari penggunaan smartphone berlebihan oleh peserta didik diluar institusi sekolah dan dapat meminimalisir tindakan Persekusi (bullying) terhadap teman sekelasnya yang dianggap tidak melek Tehnologi (gaptek), dan juga sikap minder atau pendiam peserta didik karena merasa lebih rendah dari anak lain yang seusia karena tidak mengenal smartphone dalam kehidupannya.

Dengan memasukan smartphone kedalam kurikulum pendidikan disekolah, diharapkan pula agar Pembatasan - pembatasan perlu dilakukan terutama Sebagai orang tua, sebaiknya mereka membimbing dan memantau serta memberikan pemahaman yang baik kepada anak untuk lebih selektif dalam memilih permainan (game) yang terdapat pada smartphone. 


\section{DAFTAR PUSTAKA}

\section{Buku}

[1] Piaget, J \& Cook, M. T, 1952. The origins of intelligence in children. International University Press,..New York

[2] Anita E. Woolfolk, 2011. Educational Psychology, Allyn and Bacon,.USA

[3] Desmita, 2015. Psikologi Perkembangan, Rosda,. Bandung

[4] J.P.Chaplin, 2016.Kamus Lengkap Psikologi, Raja Grafindo Persada,. Jakarta

[5] Syamsu Yusuf, 2011.Psikologi Perkembangan Anak dan Remaja, PT. Remaja Rosdakarya,. Bandung

[6] Shapiro, Lawrence E, 2011.Mengajarkan Emotional Intelligence pada Anak, PT Gramedia Pustaka Utama,. Jakarta

[7] Dharma, Kusuma Kelana, 2011.Metodologi Penelitian Keperawatan :Panduan Melaksanakan dan Menerapkan Hasil Penelitian, Trans InfoMedia,. Jakarta

[8] Santrock, W. J, 2017. Perkembangan Anak, Erlangga,. Jakarta

\section{Jurnal}

[9] Bahtiar, (2015). Hubungan antara Kecerdasan Emosional dengan Prestasi Belajar Siswa Kelas II SMA Negeri 2 Mataram, Mataram: Jurnal Pemikiran Alternatif Kependidikan: Vol. 14. No. 2. (254-268) Mei Agustus 2009

\section{Artikel}

[10] Theva Nifty, (2018). Survei Tentang Smartphone \& Tablet Hasilnya Mengejutkan. From: https://id.theasianparent.com/hasil-survey-smartphone-yang-mengejutkan diakses tanggal 20 Februari 2020

[11] Bagus Pradana, (2019). Satu dari Empat Anak Kecanduan Smartphone, From: https://mediaindonesia.com/read/detail/275141-satu-dari-empat-anak-kecanduansmartphone, diakses tanggal 2 maret 2020. 